Dimethyl sulfoxide에 의한 세포내 칼슘이온 농도 증가가 안정적으로 형질 전환된 초파리 S2 세포에서 재조합 사람 cyclooxygenase 1의 발현에 미치 는 영향

장경화 ${ }^{1}$, 박종화 ${ }^{1}$, 김도형 ${ }^{1}$, 정하영 ${ }^{1}$, 황보전 ${ }^{1}$, 이현호 $^{1}$, 이희영 ${ }^{2}$, 손동화 ${ }^{3}$, 김원용 ${ }^{4}$, 정인식 $^{1 *}$

\title{
An Increased Intracellular Calcium Ion Concentration in Response to Dimethyl Sulfoxide Correlates with Enhanced Expression of Recombinant Human Cyclooxygenase 1 in Stably Transfected Drosophila melanogaster S2 Cells
}

Kyung Hwa Chang ${ }^{1}$, Jong-Hwa Park ${ }^{1}$, Do Hyung Kim ${ }^{1}$, Ha Young Chung ${ }^{1}$, Jeon Hwang-Bo ${ }^{1}$, Hyun Ho Lee ${ }^{1}$, Hee-Young Lee ${ }^{2}$, Dong-Hwa Shon ${ }^{3}$, Wonyong Kim ${ }^{4}$, and In Sik Chung ${ }^{1 *}$

접수: 2012년 8월 17일 / 게재승인: 2012년 10월 10일

(C) 2012 The Korean Society for Biotechnology and Bioengineering

\begin{abstract}
Dimethyl sulfoxide (DMSO) increased the intracellular calcium ion concentration in stably transfected Drosophila melanogaster S2 cells expressing recombinant cyclooxygenase 1 (COX-1). DMSO did not increase the Drosophila NOS (dNOS) transcript level in calcium chelatortreated cells. Expression of recombinant COX-1 due to DMSO was diminished in cells treated with calcium chelators or channel blockers. Our results indicate that an increased intracellular calcium ion concentration due to DMSO is associated with up-regulation of the $d N O S$ gene, leading to enhanced expression of COX-1.
\end{abstract}

\footnotetext{
${ }^{1}$ Department of Genetic Engineering and Graduate School of Biotechnology, Kyung Hee University, Yongin 446-701, Korea Tel: +82-31-201-2436, Fax: +82-31-202-9885 e-mail: ischung@khu.ac.kr

${ }^{2}$ Medican Co., Ltd., Seoul 135-891, Korea

${ }^{3}$ Korea Food Research Institute, Seongnam-si, Kyunggi-do 463746 , Korea,

${ }^{4}$ Department of Microbiology \& Research Institute for Translational System Biomics, Chung-Ang University College of Medicine, Seoul 156-756, Korea
}

Keywords: recombinant cyclooxygenase 1, dimethyl sulfoxide, Drosophila melanogaster $\mathrm{S} 2$ cells, calcium ion

\section{Introduction}

Drosophila melanogaster Schneider 2 (S2) cells have been widely used for heterologous gene expression [1]. S2 cells provide a null background for studying heterologous gene product and allow stable insertion of up to several hundred gene copies into the chromosomal DNA. In addition, S2 cells grow readily in suspension to high densities. The most important advantage of the $\mathrm{S} 2$ cell expression system is an availability of both strong constitutive and tightly regulated inducible promoters. The Drosophila actin 5C and metallothionein (MT) promoters are well characterized constitutive and inducible promoter, respectively, to allow high level expression of interest gene in Drosophila S2 cells [2,3].

Metallothioneins (MTs) are ubiquitous low-molecular-weight cysteine-rich proteins that bind heavy metals (i.e., $\mathrm{Cu}, \mathrm{Zn}$, $\mathrm{Cd}$ ) and seem to protect organisms from toxic metals $[4,5]$. MTs are involved in zinc ion homeostasis. In experimental 
transformation of animals and cultures, the MT gene regulatory 5 ' region has been shown to be an efficient promoter in chimeric gene constructs. The Drosophila MT promoter is known to allow high-level, inducible expression of a gene of interest in S2 cells [6,7]. When used to express heterologous proteins, the MT promoter is extremely efficient and tightly regulated [7]. The MT promoter is inducible by addition of copper sulfate, cadium chloride, or metal ions to the culture medium [8].

Dimethyl sulfoxide (DMSO) is an effective cell permeabilizing agent that penetrates cellular membranes and helps the release of intracellular products from cells. DMSO has been reported to show several biological effects and is used as a stabilizing agent for protein [9]. DMSO increases the efficiency of DNA transfer in Escherichia coli by the combination with divalent calcium ion [10]. In mammalian cells, DMSO treatment increases the transfection efficiency after electroporation [11]. DMSO has been reported to induce morphological changes in mouse erythroleukemic cells [12]. DMSO regulates differentiation in neuroblastoma cells [13]. DMSO is thought to have a broad impact on many aspects of gene expression in animal and insect cells [14-16]. DMSO enhanced the production of recombinant proteins such as rotavirus VP7, human cyclooxygenase 1 and 2 (COX-1 and 2) from stably transfected $\mathrm{S} 2$ cells [17-19]. Recently, we reported that DMSO increased synthesis of Drosophila NOS (dNOS) at both the RNA and protein levels, and that dNOS expression is closely related to synthesis of recombinant COX-1 mRNA in stably transfected S2 cells [19]. The activity of the $d N O S$ gene in the Drosophila genome is known to be calcium/calmodulin dependent [20]. We postulated that DMSO affects the changes in the intracellular calcium ion concentration associated with up-regulation of NOS activity, leading to enhanced expression of recombinant COX-1 in stably transfected S2 cells via up-regulation of the MT promoter. Therefore, in this study, we first attempted to elucidate the relationship between the intracellular calcium ion concentration and expression of recombinant COX-1 in stably transfected S2 cells after DMSO treatment.

\section{Materials and Methods}

\subsection{Cell culture}

Stably transfected S2 cells expressing recombinant COX-1 were generated via co-transfection with $\mathrm{pMT} / \mathrm{BiP}-\mathrm{His}-\mathrm{COX}-1$ and pCoHygro [19]. Stably transfected S2 cells were grown at $27^{\circ} \mathrm{C}$ in T-25 flasks in $3 \mathrm{~mL}$ of Shields and Sang M3 insect medium (Sigma-Aldrich, St. Louis, MO, USA) containing $10 \%$ insect medium supplementary (IMS, Sigma-Aldrich) and $300 \mu \mathrm{g} / \mathrm{mL}$ hygromycin B. Expression of recombinant
COX-1 from stably transfected S2 cells was induced by $0.5 \mathrm{mM}$ $\mathrm{CuSO}_{4}$ after the start of the run. To determine the effect of DMSO on gene expression, DMSO was added at $6 \%(\mathrm{v} / \mathrm{v})$ to the cultures, 5 days post-innoculation.

\subsection{Measurement of intracellular calcium ion concentration}

Intracellular calcium ion concentrations were determined by calcium measurements using Wallac VICTOR ${ }^{2}$ plate reader (PerkinElmer Life Sciences, Inc., Boston, MA, USA), according to the manufacturer's instruction. Briefly, stably transfected $\mathrm{S} 2$ cells $\left(5 \times 10^{5}\right.$ cells $)$ were incubated for indicated times in the presence or absence of $6 \%$ DMSO. Cells were washed with Hank's basal saline solution (HBSS; $20 \mathrm{mM}$ HEPES, $1 \mathrm{mM} \mathrm{CaCl}_{2}, 1 \mathrm{mM} \mathrm{MgCl}_{2}$, and $2.5 \mathrm{mM}$ probenecid, $\mathrm{pH}$ 7.0). Cells were resuspended in $100 \mu \mathrm{L}$ of HBSS containing $4.5 \mu$ M Fluo-AM (Molecular Probes, Eugene, OR, USA) and $0.01 \%$ pluronic acid, followed by an incubation in darkness for $40 \mathrm{~min}$ at $27^{\circ} \mathrm{C}$. After washing twice with HBSS, cells were resuspended in $50 \mu \mathrm{L}$ of HBSS and transferred to 96-well plates. The fluorescence was measured with Wallac VICTOR $^{2}$ plate reader. The excitation and emission wavelengths were $488 \mathrm{~nm}$ and $530 \mathrm{~nm}$, respectively.

\subsection{SDS-PAGE and Westem blot analysis}

Stably transfected S2 cell cultures were centrifuged at $3,000 \mathrm{rpm}$ for $5 \mathrm{~min}$ to separate the cells. The supernatant was used to identify extracellular recombinant proteins. The cell fraction was rocked for $1 \mathrm{~h}$ in a lysis buffer $(50 \mathrm{mM}$ Tris- $\mathrm{Cl}$ at $\mathrm{pH} 8.0,150 \mathrm{mM} \mathrm{NaCl}, 0.02 \%$ sodium azide, $100 \mu \mathrm{g} / \mathrm{mL}$ phenylmethylsulfonyl fluoride, $1 \mu \mathrm{g} / \mathrm{mL}$ aprotinin, and $1 \%$ Triton $\mathrm{X}-100$ ) and subjected to three freeze-thaw cycles of $10 \mathrm{~min}$ in a $-70^{\circ} \mathrm{C}$ freezer and $5 \mathrm{~min}$ in a $37^{\circ} \mathrm{C}$ water bath. After centrifuging the cell extracts at $14,000 \mathrm{rpm}$ for 15 min to remove cell debris, the supernatant was used to identify intracellular recombinant proteins. Protein samples were separated by electrophoresis on $8 \%$ polyacrylamidesodium dodecyl sulfate (SDS) gel and transferred to a nitrocellulose membrane (Amersham Pharmacia, Piscataway, NJ, USA). The membranes were blocked with 3\% BSA (bovine serum albumin) and incubated in 1\% BSA with mouse anti-human COX-1 monoclonal antibody (1:1,000 dilution; Cayman Chemical, Ann Arbor, MI, USA). After probing with alkaline phosphatase-conjugated goat antimouse-IgG antibody (1:1,000 dilution; Sigma-Aldrich). The membranes were washed and a BM purple AP substrate solution (Boehringer Mannheim, Germany) was applied to detect protein bands. The reaction was quenched with distilled water.

\subsection{Northem blot analysis}

Total RNA was isolated using an RNeasy Mini Kit (Qiagen, 
Valencia, CA, USA) from stably transfected $\mathrm{S} 2$ cells treated with DMSO and BAPTA-AM [1,2-bis(2-aminophenoxy) ethane-N,N,N',N'-tetraacetic acid tetrakis(acetoxymethyl ester); Sigma-Aldrich]. RNAs were separated by electrophoresis in $1 \%$ agarose gel under denaturing conditions containing formaldehyde, transferred to a Hybond- $\mathrm{N}^{+}$membrane (Amersham Pharmacia) using the capillary transfer method, and fixed by exposure to ultraviolet (UV) light (CL-1000 Ultraviolet Crosslinker; UVP, Upland, CA, USA). The $d N O S$ gene fragment was labeled using the Prime-A-Gene Labelling System (Promega, Madison, WI, USA) with $\left[\alpha{ }^{32} \mathrm{P}\right] \mathrm{dATP}$, then used as a probe. The membrane was hybridized overnight at $65^{\circ} \mathrm{C}$ in a hybridization mixture (6x SSC, $0.2 \%$ Denhardt's solution, $0.5 \%$ SDS, $100 \mu \mathrm{g} / \mathrm{mL}$ of salmon sperm DNA) containing the $\left[\alpha-{ }^{32} \mathrm{P}\right] \mathrm{dATP}$-labelled probe. The membrane was then washed three times with a washing solution $(0.1 \mathrm{x}$ SSC, $0.1 \% \mathrm{SDS}$ ) at $65^{\circ} \mathrm{C}$ for $10 \mathrm{~min}$, followed by autoradiography at $-70^{\circ} \mathrm{C}$ using X-ray film (Kodak, Rochester, NY, USA).

\section{Results and Discussion}

\subsection{Effect of DMSO on expression of recombinant COX-1 from stably transfected $S 2$ cells}

In our previous work, we generated stably transfected Drosophila S2 cells expressing recombinant COX-1 [19]. Recombinant COX-1 was expressed in the cellular fraction of stably transfected S2 cells with molecular weights of 68 $\mathrm{kDa}$ and $74 \mathrm{kDa}$, due to glycosylation. A $72 \mathrm{kDa}$ COX-1 was observed in the medium fraction of stably transfected S2 cells [19]. To determine the effects of DMSO on expression of recombinant COX-1, DMSO was added to the cultures at 5 day post-inoculation in the presence or absence of $\mathrm{CuSO}_{4}$. Supplementation of cultures with $6 \%$ DMSO increased recombinant COX-1 production by $180 \%$ compared to $\mathrm{CuSO}_{4}$ treated cells [19]. DMSO induces expression of recombinant COX-1 without $\mathrm{CuSO}_{4}$ supplementation. Enhancement of recombinant COX-1 production due to DMSO was only observed in S2 cells transfected with a construct of the MT promoter, but not the actin $5 \mathrm{C}$ promoter. This suggests that DMSO increases production of recombinant COX-1 though up-regulation of the MT promoter.

\subsection{Effect of DMSO on intracellular calcium ion concentration} DMSO has been reported to transiently increase the calcium ion concentration in various cell types including primary cultures of chicken ovarian granulose cells, undifferentiated P19 embryonal carcinoma cells, 3T3-L1 fibroblasts, Friend murine erythroleukemia (MEL) cells, and hepatocytes [21,22]. To determine the effect of DMSO on the cellular calcium ion concentration in S2 cells, stably transfected S2 cells were incubated for indicated times in the presence and absence of $6 \%$ DMSO and the intracellular calcium ion concentrations were determined. The intracellular calcium ion concentration in stably transfected $\mathrm{S} 2$ cells cultured in the presence of $6 \%$ DMSO dramatically increased up to $9 \mathrm{~h}$, after then gradually decreased (Fig. 1). In RPMI-8402 human T lymphoblasotoid cells, DMSO increased the intracellular calcium ion concentration with a maximum concentration at $24 \mathrm{~h}$ after DMSO treatment [23]. This indicates that DMSO increases the intracellular calcium ion concentration in S2 cells and also suggests that the modification of intracellular calcium ion concentration due to DMSO might affect the induction of MT promoter.

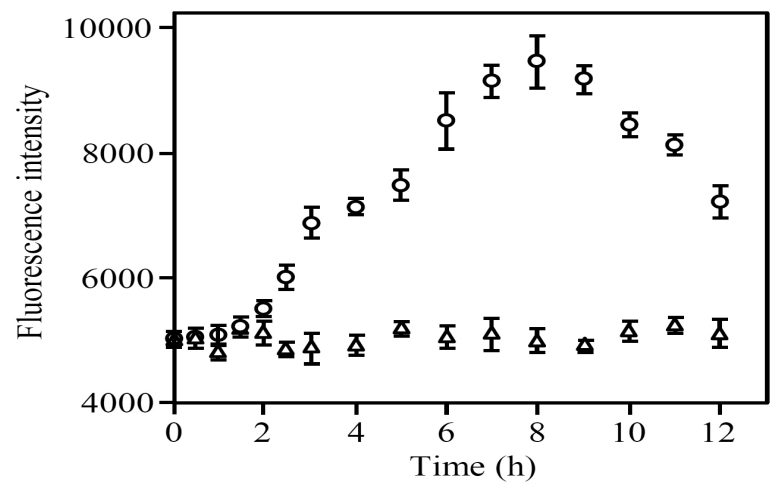

Fig. 1. The effect of DMSO on the cytoplasmic calcium ion concentration in stably transfected S2 cells. Open circle and up-triangle indicate relative fluorescence units of stably transfected $\mathrm{S} 2$ cells incubated in the presence and absence of $6 \%$ DMSO, respectively. Data represent the mean \pm standard deviation from three independent experiments.

\subsection{Effect of the intracellular calcium ion concentration on up-regulation of the dNOS transcript by DMSO}

Calcium is known to act both in the cytoplasm and the nucleus to activate signaling pathways that stimulate gene expression through different DNA regulatory elements [24]. In our previous work, DMSO increased synthesis of Drosophila NOS (dNOS) at both the RNA and protein levels. dNOS expression was closely related to synthesis of recombinant COX-1 mRNA in stably transfected S2 cells [19]. Nitric oxide synthases (NOSs) synthesize nitric oxide (NO), a short-lived molecule that reacts with $\mathrm{O}_{2}$, transition-metal ions, and thiols, during conversion of L-arginine to L-citrulline in many cell types $[25,26]$. The $d N O S$ located on the second chromosome at cytological position 32B is the only gene for NOS in the Drosophila genome. Its activity is known to be calcium/ calmodulin dependent [20]. To determine the effect of the intracellular calcium ion concentration on up-regulation of the $d N O S$ transcript by DMSO, stably transfected S2 cells were treated with $6 \%$ DMSO in the presence of BAPTA-AM, an intracellular calcium ion chelator. Total RNA was isolated from stably transfected S2 cells and Northern blot analysis 
was performed to determine the level of the $d N O S$ transcript. In stably transfected $\mathrm{S} 2$ cells, the $d N O S$ transcript level was increased for up to $9 \mathrm{~h}$, remained relatively constant for 12-18 $\mathrm{h}$, then decreased slightly at $24 \mathrm{~h}$ [19]. However, the $d N O S$ transcript level was not affected in stably transfected S2 cells treated with DMSO in the presence of BAPTA-AM (Fig. 2). This indicates that the increase of $d N O S$ transcript level due to DMSO is mediated by enhancement of the intracellular calcium ion concentration.

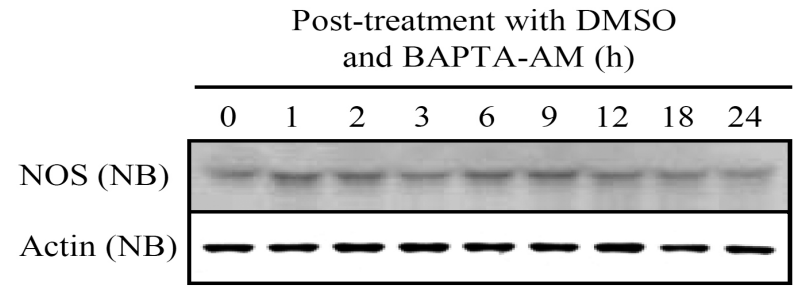

Fig. 2. The effect of DMSO on the $d N O S$ transcript level in BAPTAAM treated stably transfected S2 cells. Any noticeable effects on cell viability were not observed at a concentration of $250 \mu \mathrm{M}$ BAPTA-AM. NB means Northern blot analysis.

\subsection{Effect of calcium chelators on expression of recombinant COX-1 in DMSO-treated stably transfected $\mathbf{S 2}$ cells}

The effect of BAPTA-AM on expression of recombinant COX-1 in DMSO-treated stably transfected S2 cells was further determined (Fig. 3(a)). DMSO and BAPTA-AM were added to cultures at 5 days post-inoculation. After 2 days of incubation, expression of recombinant COX-1 in both the cellular and medium fractions was determined using Western blot analysis with the anti-human COX-1 monoclonal antibody. The presence of BAPTA-AM decreased expression of recombinant COX-1 in response to DMSO. Expression of

(a)

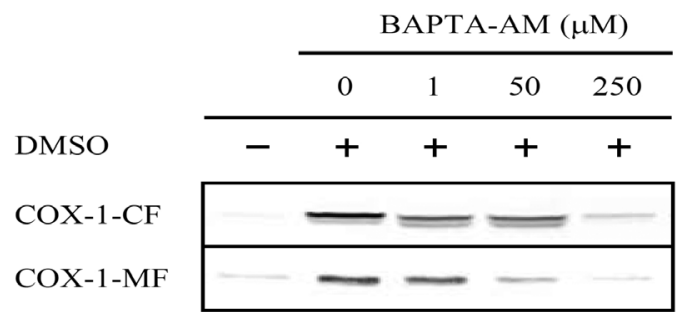

(b)

\begin{tabular}{|c|c|c|c|c|c|c|}
\hline & & & & TA $(\mathrm{n}$ & & \\
\hline & & 0 & 1 & 2.5 & 5 & 10 \\
\hline DMSO & - & + & + & + & + & + \\
\hline COX-1-CF & & $=$ & 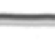 & 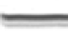 & - & \\
\hline COX-1-MF & & $=$ & - & $m-$ & - & \\
\hline
\end{tabular}

Fig. 3. The effect of the calcium chelators BAPTA-AM (a) and EGTA (b) on expression of recombinant COX-1 due to DMSO. Any noticeable effects on cell viability were not observed at a concentration of either $250 \mu \mathrm{M}$ BAPTA-AM or $10 \mathrm{mM}$ EGTA. CF and MF indicate cellular fraction and medium fraction, respectively. recombinant COX-1 due to DMSO in both the intracellular and medium fractions was diminished to the basal level at a concentration of $250 \mu \mathrm{M}$. Expression of recombinant COX-1 due to DMSO was also determined in calcium ion chelator, ethylene glycol tetraacetic acid (EGTA)-treated stably transfected S2 cells (Fig. 3(b)). EGTA treatment reduced expression of recombinant COX-1 in both the intracellular and medium fractions. In $10 \mathrm{mM}$ EGTA-treated S2 cells, expression of recombinant COX-1 due to DMSO was reduced to the basal level. These results indicate that chelating the calcium ion reduces expression of recombinant COX-1 due to DMSO.

\subsection{Effect of calcium channel blockers on expression of recombinant COX-1 in DMSO-treated stably transfected S2 cells}

DMSO has been suggested to increase the calcium ion concentration via two mechanisms of 1) release of the ion from intracellular pools and, 2) stimulation of an influx across the plasma membrane [27]. Several classes of calcium entry channel have been documented in insects, including L-type calcium channel subunits. L-type calcium channels regulate epithelial fluid transport in Drosophila melanogaster [28]. To evaluate whether the increase in the intracellular calcium ion level due to DMSO is caused by stimulation of an influx across the plasma membrane, expression of recombinant COX-1 due to DMSO was determined in calcium channel blocker-treated stably transfected S2 cells. DMSO and calcium channel blockers were added to the culture at 5 days post-inoculation. After 2 days of incubation, expression of recombinant COX-1 in both the cellular and medium fractions was determined

(a)

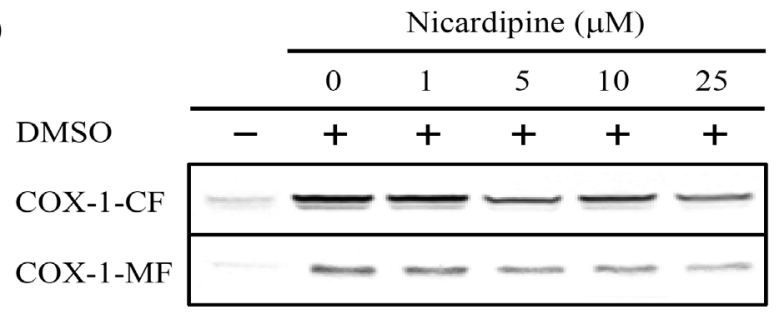

(b)

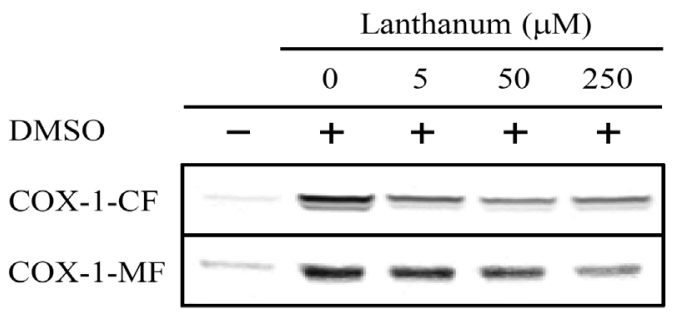

Fig. 4. The effect of the calcium channel blockers nicardipine (a) and lanthanum (b) on expression of recombinant COX-1 due to DMSO. Any noticeable effects on cell viability were not observed at a concentration of either $25 \mu \mathrm{M}$ nicardipine or $250 \mu \mathrm{M}$ lanthanum. CF and $\mathrm{MF}$ indicate cellular fraction and medium fraction, respectively. 
by Western blot analysis. As shown in Fig. 4(a) and (b), expression of recombinant COX-1 due to DMSO was decreased by treatment with the calcium channel blockers nicardipine, an L-type voltage-dependent calcium ion blocker, and lanthanum, a calcium ion channel-entry blocker. Treatment with $25 \mu \mathrm{M}$ nicardipine and $250 \mu \mathrm{M}$ lanthanum reduced expression of recombinant COX-1 by $40 \%$ and $45 \%$, respectively. In addition, exogenous supplementation with calcium chloride up to $28 \mathrm{mM}$ did not improve expression of recombinant COX-1 in the absence of DMSO (data not shown). These indicates that an increase in the intracellular calcium ion concentration due to DMSO is probably caused by stimulation of a calcium ion influx across the plasma membrane.

\section{Conclusions}

DMSO increased intracellular calcium ion concentrations in stably transfected Drosophila $\mathrm{S} 2$ cells expressing recombinant COX-1. In calcium chelator-treated cells, DMSO did not increased the expression of $d N O S$ transcript, which is closely related to synthesis of recombinant COX-1 mRNA in stably transfected S2 cells [19]. Expression of recombinant COX-1 due to DMSO was diminished in cells treated with calcium chelators or channel blockers. Our results indicate that an increased intracellular calcium ion concentration due to DMSO is associated with up-regulation of the $d N O S$ gene, leading to enhanced expression of recombinant COX-1 in stably transfected S2 cells via induction of the MT promoter.

\section{Acknowledgement}

This work was supported by a grant from the Next-Generation BioGreen 21 Program (PJ008325), Rural Development Administration, Republic of Korea.

\section{References}

1. Moraes, A. M., S. A. Jorge, R. M. Astray, C. A. Suazo, C. E. Calderón Riquelme, E. F. Augusto, A. Tonso, M. M. Pamboukian, R. A. Piccoli, M. F. Barral, and C. A. Pereira (2012) Drosophila melanogaster S2 cells for expression of heterologous genes: from gene cloning to bioprocess development. Biotechnol. Adv. 30: 613-628.

2. Angelichio, M. L., J. A. Beck, H. Johansen, and M. Ivey-Hoyle (1991) Comparison of several promoters and polyadenylation signals for use in heterologous gene expression in cultured Drosophila cells. Nucleic Acids Res. 19: 5037-5043.

3. Maroni, G., E. Otto, and D. Lastowski-Perry (1986) Molecular and cytogenetic characterization of a metallothionein gene of Drosophila. Genetics 112: 493-504.
4. Hamer, D. H. (1986) Metallothionein. Annu. Rev. Biochem. 55: 913-951.

5. Palmiter, R. D. (1998) The elusive functions of metallothioneins. Proc. Natl. Acad. Sci. USA 95: 8428-8430.

6. Otto, E., J. M. Allen, J. E. Young, R. D. Palmiter, and G. Maroni (1987) A DNA segment controlling metal-regulated expression of the Drosophila melanogaster metallothionein gene MTn. Mol. Cell Biol. 7: 1710-1715.

7. Johansen, H., A. van der Straten, R. Sweet, E. Otto, G. Maroni, and M. Rosenberg (1989) Regulated expression at high copy number allows production of a growth inhibitory oncogene product in Drosophila schneider cells. Genes and Development 3: 882-889.

8. Bunch, T. A., Y. Grinblat, and L. S. Goldstein (1988) Characterization and use of the Drosophila metallothionein promoter in cultured Drosophila melanogaster cells. Nucleic Acids Res. 16: 1043-1061.

9. Wahl, M. F., G. H. An, and J. M. Lee (1995) Effects of dimethylsulfoxide on heavy chain monoclonal antibody production from plant cell culture. Biotechnol. Lett. 17: 463-468.

10. Hanahan, D. (1983) Studies on transformation of Escherichia coli with plasmids. Mol. Biol. 166: 557-580.

11. Melkonyan, H., C. Sorg, and M. Klempt (1996) Electroporation efficiency in mammalian cells is increased by dimethyl sulfoxide (DMSO). Nucleic Acids Res. 24: 4356-4357.

12. Yenofsky, R., S. Cereghini, A. Krowczynska, and G. Brawerman (1983) Regulation of mRNA utilization in mouse erythroleukemia cells induced to differentiate by exposure to dimethyl sulfoxide. Mol. Cell Biol. 3: 1197-1203.

13. Pollerberg, G. E., M. Schachner, and J. Davoust (1986) Differentiation state-dependent surface mobilities of two forms of the neural cell adhesion molecule. Nature 324: 462-465.

14. Wang, W., X. Yi, and Y. Zhang (2007) Gene transcription acceleration: main cause of hepatitis $B$ surface antigen production improvement by dimethylsulfoxide in the culture of Chinese hamster ovary cells. Biotechnol. Bioeng. 97: 526-535.

15. Sumida, K., Y. Igarashi, N. Toritsuka, T. Matsushita, K. AbeTomizawa, M. Aoki, T. Urushidani, H. Yamada, and Y. Ohno (2011) Effects of DMSO on gene expression in human and rat hepatocytes. Human Exp. Toxicol. 30: 1701-1709.

16. Gouveia, R., S. Kandzia, H. S. Conradt, and J. Costa (2010) Production and $N$-glycosylation of recombinant human adhesion molecule L1 from insect cells using the stable expression system. Effect of dimethyl sulfoxide. J. Biotechnol. 145: 130-138.

17. Park, J. H., K. H. Chang, Y. H. Lee, H. Y. Kim, J. M. Yang, and I. S. Chung (2002) Production of recombinant rotavirus capsid protein VP7 from stably transformed Drosophila melanogaster S2 cells. J. Microbial. Biotechnol. 12: 563-568.

18. Chang, K. H., J. H. Park, Y. H. Lee, J. H. Kim, H. O. Chun, J. H. Kim, and I. S. Chung (2002) Dimethyl-sulfoxide and sodium butyrate enhance the production of recombinant cyclooxygenase 2 in stably transformed Drosophila melanogaster S2 cells. Biotechnol. Lett. 24: 1353-1359.

19. Chang, K. H., J. H. Park, H. Y. Chung, J. Hwang-Bo, H. H. Lee, D. H. Kim, Y. Soh, and I. S. Chung (2012) Enhanced expression of recombinant human cyclooxygenase 1 from stably-transfected Drosophila melanogaster $\mathrm{S} 2$ cells by dimethyl sulfoxide is mediated by up-regulation of nitric oxide synthase and transcription factor Kr-h1. Biotechnol. Lett. 34: 1243-1250.

20. Regulski, M. and T. Tully (1995) Molecular and biochemical characterization of dNOS: Drosophila $\mathrm{Ca}^{2+} /$ calmodulin- 
dependent nitric oxide synthase. Proc. Natl. Acad. Sci. USA 92: 9072-9076.

21. Morley, P. and J. F. Whitfield (1993) The differentiation inducer, dimethyl sulfoxide, transiently increases the intracellular calcium ion concentration in various cell types. J. Cell Physiol. 156: 219-225.

22. Yamamoto, N. (1989) Effect of dimethyl sulfoxide on cytosolic ionized calcium concentration and cytoskeletal organization of hepatocytes in a primary culture. Cell Struct. Funct. 14: 75-85.

23. Trubiani, O., C. Pieri, M. Rapino, and R. Di Primito (1999) The c-myc gene regulates the polyamine pathway in DMSOinduced apoptosis. Cell Prolif. 32: 119-129.

24. Bading, H., G. E. Hardingham, C. M. Johnson, and S. Chawla
(1997) Gene regulation by nuclear and cytoplasmic calcium signals. Biochem. Biophys. Res. Commun. 236: 541-543.

25. Marletta, M. A. (1994) Nitric oxide synthase: aspects concerning structure and catalysis. Cell 78: 927-930.

26. Nathan, C. and Q. Xie (1994) Nitric oxide synthases: roles, tolls, and controls. Cell 78: 915-918.

27. Putney, J. W. (1990) Capacitive calcium entry revisited. Cell Calcium 11: 611-624.

28. MacPherson, M. R., V. P. Pollock, K. E. Broderick, L. Kean, F. C. O'Connell, J. A. Dow, and S. A. Davies (2001) Model organisms: new insights into ion channel and transport function. L-type calcium channels regulate epithelial fluid transport in Drosophila melanogaster. Am. J. Physiol. Cell Physiol. 280: C394-407. 